\title{
Brasil: o acesso universal ao saneamento básico
}

\author{
Brazil: universal access to sanitation \\ Jordana Georgin', Laudison Lazzari ${ }^{2}$, Jussara da Cruz Cabral ${ }^{3}$, Lucas Damo Marangoni ${ }^{4}$ \\ 'Mestranda em engenharia ambiental, Universidade Federal de Santa Maria \\ 2Engenheiro agrônomo, Universidade Federal de Santa Maria \\ ${ }^{3}$ Professora, Departamento de engenharia civil, Universidade Federal de Santa Maria \\ ${ }^{4}$ Mestrando na agrobiologia, Universidade Federal de Santa Maria
}

\section{Resumo}

O saneamento é um direito fundamental e deve ser oferecido pelo Poder Público, porém atualmente este serviço não esta sendo prestado adequadamente. $\mathrm{O}$ acesso regular a água potável e segura tem causado preocupação, principalmente em países em desenvolvimento e, mais enfaticamente em áreas periurbanas, que abrigam a população socialmente excluída. A falta ou a precariedade do acesso água representa situação de risco que propicia aumento da incidência de doenças infecciosas agudas e da prevalência de doenças crônicas. O caminho para reverter esse cenário e a implementação integrada de politicas públicas de gestão, que envolvam ações conjuntas e ajustadas nos setores de desenvolvimento urbano, habitação, saneamento e saúde e que visem à promoção e a proteção da saúde da população local e ao enfrentamento da complexidade de fatores que evidenciam sua vulnerabilidade. O seguinte trabalho teve como objetivo analisar a atual situação de acesso ao saneamento básico no Brasil, os problemas que a falta deste recurso pode gerar, bem como o dever do Estado mediante a esta situação.

Palavras-chaves: Saneamento básico; Doenças; Poder público.

\begin{abstract}
Sanitation is a fundamental right and should be provided by the Government, but currently this service is not being provided adequately. Regular access to safe drinking water has caused concern, particularly in developing countries and, more emphatically in peri-urban areas, which house the socially excluded population. The lack or precarious access is water hazard that increases the incidence of acute infectious diseases and the prevalence of chronic diseases. The way to reverse this scenario and integrated implementation of public management policies, involving joint actions in the set and urban development, housing, sanitation and health sectors and for the promotion and protection of health of the local population and to cope with the complexity of factors that reveal their vulnerability. The next job was to analyze the current situation of access to basic sanitation in Brazil, the problems that the lack of this feature can generate, and the duty of the State by this situation.
\end{abstract}

Keywords: Sanitation; Diseases; Public power. 


\section{INTRODUÇÃO}

Com o advento da Lei $\mathrm{n}^{\circ} 11.445 / 07$, foi cunhado o conceito de saneamento básico como o conjunto de serviços, infraestruturas e instalações de abastecimento de água, esgotamento sanitário, limpeza urbana e manejo de resíduos sólidos e drenagem de águas pluviais urbanas.

A lei definiu também as competências quanto à coordenação e atuação dos diversos agentes envolvidos no planejamento e execução da política federal de saneamento básico no País. Em seu art. 52 a lei atribui ao Governo Federal, sob a coordenação do Ministério das Cidades, a responsabilidade pela elaboração do Plano Nacional de Saneamento Básico (Plansab).

A questão do planejamento do setor já foi objeto de vários debates e do posicionamento do Conselho das Cidades que editou a Resolução Recomendada $n^{\circ} .33$, de $1^{\circ}$ de março de 2007, estabelecendo prazos e instituindo um Grupo de Trabalho integrado por representantes do Governo Federal para o acompanhamento da elaboração do PLANSAB.

A esse aspecto, soma-se o compromisso do País com os objetivos do Milênio das Nações Unidas e a instituição de 2009 - 2010 como o Biênio Brasileiro do Saneamento (Decreto n ${ }^{\circ}$ 6.942/09), com o propósito de mobilizar para o alcance da meta de, até o ano de 2015 , reduzir pela metade a proporção de pessoas que não contam com saneamento básico.

A título de subsídio, a SRHU/DAU, entre outras ações, promoveu a realização de uma oficina em 29 de outubro de 2008, em Brasília, DF. O objetivo da oficina foi de extrair os aspectos fundamentais da problemática dos Resíduos Sólidos Urbanos - RSU para o planejamento de curto, médio e longo prazo no âmbito do Plano Nacional de Saneamento Básico.

Após o lançamento, em dezembro de 2008, do "Pacto pelo Saneamento Básico: mais saúde, qualidade de vida e cidadania", documento cujo propósito é buscar a adesão e o compromisso de toda a sociedade em relação aos eixos, estratégias e ao processo de elaboração do PLANSAB, ingressa-se na fase de elaboração do "Panorama do Saneamento Básico no Brasil".

Em decorrência do "Pacto pelo Saneamento Básico", o Ministério do Meio Ambiente e o Ministério das Cidades decidiram firmar o "Compromisso pelo Meio Ambiente e Saneamento Básico" que consiste em um conjunto de ações em curso ou a serem estruturadas para atingir metas intermediárias preconizadas pela Lei de Saneamento Básico até o ano de 2020. Com o objetivo de construir e contribuir para a definição conjunta de ações e programas de grande relevância para o setor de saneamento, o "Compromisso" resulta de uma ampla reflexão sobre as tendências e os desafios atuais do saneamento básico no Brasil.

Portanto esta revisão bibliográfica teve como objetivo analisar a atual situação de acesso ao saneamento básico no Brasil, as autoridades responsáveis, bem como as desigualdades no acesso a este recurso, e por fim as consequências à saúde que isso pode acarretar.

\section{MATERIAIS E MÉTADOS}

A revisão bibliográfica realizada, alicerça-se em analisar a atual situação do acesso ao saneamento básico no Brasil, as classes atendidas e as esquecidas pelo poder público, as consequências trazidas a saúde, o papel do Estado mediante este cenário, e as alternativas que podem modificar esta realidade do país.

\section{RESULTADOS E DISCUSSÕES}

\subsection{Problemas acarretados pela falta de Saneamento}

Especialistas listam vários benefícios que o investimento em saneamento pode gerar, dentre eles: "melhoria da saúde da população, diminuição dos custos de tratamento da água para abastecimento, melhoria do potencial produtivo das pessoas, conservação ambiental e reconhecimento dos eleitores".

Em 1996, em Mato Grosso do Sul houve 111 casos confirmados de malária. No mesmo ano a taxa de mortalidade por doenças infecciosas e parasitárias a cada cem mil habitantes foi de $26,71 \%$. Em 2008 houve 648 casos de dengue a cada cem mil habitantes. 
Em 2007 morreram em Mato Grosso do Sul 558 pessoas por doenças infecto parasitárias, o que é lastimável e poderiam ter sido evitadas essas mortes caso tivesse investido em saneamento básico.

Uma pesquisa realizada pelo Instituto de Pesquisa Econômica Aplicada (IPEA) informa que "os serviços de saneamento básico são essenciais à vida, com fortes impactos sobre a saúde da população e o meio ambiente" (MENDONÇA, 2005).

Também, esse mesmo estudo do IPEA aponta que "ações preventivas de saneamento, em particular no tratamento da água, seriam mais justificáveis economicamente para a contínua redução da mortalidade infantil do que os gastos defensivos nos serviços de saúde".

Dessa forma, as obras de infraestrutura para prestar os serviços relativos ao saneamento, que são caracterizadas como medidas preventivas, apesar de parecerem de altos custos, são benéficas às finanças públicas do Estado, ao meio ambiente e diminuirá os gastos com saúde pública com várias doenças que são geradas pela falta de saneamento, além de perca de produtividade no trabalho devido à debilitação da saúde (HESPANHOL, 2002).

O Relatório de Desenvolvimento Humano 2007/2008 (ONU), trouxe à tona que em 1996 a taxa de mortalidade infantil dentre os vinte por cento mais pobres no Brasil era de oitenta e três a cada um mil nascidos vivos, enquanto que entre os vinte por cento mais ricos era de vinte e nove.

Dentre as crianças, a diarréia causa cinco vezes mais vítimas letais no mundo do que o HIV, apesar de ser silenciosa. Porém, a diarréia não recebe tanta atenção como as campanhas para a prevenção do HIV. É importante apresentar que a diarréia é a segunda principal causa de mortalidade infantil no mundo, após as doenças respiratórias (HESPANHOL, 2002).

Os problemas decorrentes de tal situação se refletem na persistência de enfermidades que poderiam ser prevenidas, caso houvesse um suprimento adequado de água de boa qualidade, condição indispensável para uma qualidade de vida razoável. Com efeito, por ser um bem de primeira necessidade, a água é utilizada, cotidianamente, para o preparo de alimentos, matar a sede, higiene e asseio corporal, limpeza de utensílios domésticos e da habitação, banho e descarga de vasos sanitários, dentre outros usos importantes, razão pela qual a condição existencial de não dispor de água potável em quantidade adequada compromete esses usos cotidianos, podendo expor as pessoas a riscos de adoecimento, como, também, limitar o desenvolvimento de legítimos projetos pessoais de vida. Essa questão fica evidente quando são colocadas em tela as dificuldades enfrentadas por pessoas que não têm acesso à água potável, ou o acesso que tem é precário (BRASIL, 2004).

Portanto o saneamento é um dos meios mais importantes para a promoção da saúde, art. 196 da Constituição Federal de 1988 e deve ser oferecido pelo Estado este direito. Pois as ações de saneamento se complementam com outras ações, para propiciar melhorias de vida, de forma individual ou coletiva. As doenças geradas pela falta de saneamento acabam por atingir a população mais carente. Dessa forma, causa o aumento das desigualdades entre as classes sociais. Além de afrontar os direitos fundamentais garantidos na Constituição Federal de 1988 (TUCCI, 2001).

\subsection{Papel do Estado quanto ao acesso à água potável}

Lançada há mais de um ano, a Lei n. ${ }^{\circ} 11.445 / 07$, que estabelece diretrizes nacionais para o saneamento básico, prevê princípios fundamentais, objetivos e ações que promovam a igualdade social e territorial no acesso ao saneamento básico. À letra da lei, o saneamento acontece, mas na prática a realidade é bem diferente.

Segundo a pesquisa "Impactos Sociais de Investimentos em Saneamento" da Fundação Getúlio Vargas (FGV), a falta de saneamento básico atinge $47 \%$ da população brasileira, sendo as crianças de 1 a 6 anos as principais vítimas. A pesquisa ressalta que apenas em 2122 o Brasil deve ter acesso total a esgoto. Isso porque o desenvolvimento do saneamento básico ocorre em marcha lenta e poucas são as alternativas para a prestação de serviço desse segmento.

A gestão do saneamento básico no Brasil é irregular. Nem todos os municípios possuem esse serviço, eles sofrem com a ausência de estrutura sanitária eficiente. Além disso, grandes metrópoles enfrentam a batalha causada pelo desordenamento urbano, que dissemina a população. Há ainda a influência política econômica e a desorganização social como fatores que atrasam o desenvolvimento do saneamento adequado.

No entanto, alternativas para a prestação desse serviço surgiram no país, principalmente no governo Fernando Henrique Cardoso, quando a privatização do saneamento básico no Brasil teve seu auge. Atualmente, 37 empresas estrangeiras trabalham em território brasileiro, principalmente na 
região Sudeste e Centro-Oeste. Os problemas para a implementação total da privatização no país dizem respeito às dificuldades jurídicas institucionais, o aumento da taxa de desemprego, a exploração dos recursos hídricos e a exclusão da população mais pobre na cobertura do serviço. Entre as vantagens da privatização, a esperança em contar com um serviço que, mesmo devendo ser público, pode ser oferecido adequadamente à população.

Sujeito ou não à privatização, a falta de saneamento é uma das causas de ocorrência de doenças nas populações desprovidas desse tipo de infraestrutura pública. Além disso, a falta de coleta de dejetos de esgoto contamina rios, lagos e até mananciais de água potável, por conta de seu escoamento in natura, sem o devido tratamento de esgoto. Prova disso está no alto índice de poluição nos rios e, no caso das metrópoles, o surgimento de doenças graves.

À ausência de saneamento básico associa-se, também, a problemas na saúde pública como é o caso da epidemia de dengue que registra mortes no Rio de Janeiro. Segundo a Fundação Oswaldo Cruz, a expansão desordenada dos centros urbanos onde as pessoas vivem em condições precárias, sem acesso a sistemas adequados de fornecimento de água, tratamento de esgoto e coleta de lixo, é um dos fatores que facilitam a entrada, permanência e disseminação do mosquito Aedes aegypti, causador da dengue entre elas a hemorrágica, que já matou mais de 60 pessoas. Devido a esses fatores, a Fundação adianta que a erradicação da dengue é praticamente impossível. Ela destaca que a única coisa que pode ser feita é controlar a presença do mosquito. Quanto às ações sociais e políticas, espera-se consciência e projetos para diminuir o índice de vítimas fatais.

\subsection{A desigualdade no acesso a água potável}

Além de problemas decorrentes da capacidade de pagamento, também devemos considerar os contingentes populacionais que sobrevivem à margem dos sistemas públicos, como é o caso de parte considerável não só da sociedade brasileira, mas de todo o mundo dito subdesenvolvido e em desenvolvimento. Embora os porcentuais de cobertura, em todas as regiões do mundo, já alcancem cifras elevadas, acima de $85,0 \%$, é significativa a diferença nos tipos de tecnologia em pregados, que vão determinar a precariedade e má qualidade do acesso à água potável. Enquanto a América do Norte e a Europa apresentam como tecnologia empregada, a ligação domiciliar à rede pública, para praticamente $100,0 \%$ da cobertura por abastecimento de água, África, Ásia e América Latina apresentam porcentuais bem menores. Na África, apenas $24,0 \%$ da cobertura por abastecimento de água é feita com ligações à rede pública. Na Ásia, esse percentual chega a 49,0\%, e na América Latina e Caribe o número de ligações à rede pública é de $47,0 \%$.

No Brasil, segundo dados do Censo Demográfico de 2010, as populações urbanas em piores condições de acesso à água representam um porcentual em torno de 10,0\%, ou seja, 17 milhões de habitantes, que só conseguem se abastecer de forma autônoma ou de forma clandestina em relação ao sistema público de abastecimento. Outro porcentual, ligado ao sistema público, de cerca de 5,4\% dos domicílios urbanos, o que corresponde a 7,5 milhões de pessoas, são domicílios sem canalização interna ainda de acordo com o Censo Demográfico de 2007. Isso significa que, mesmo sendo atendidos pelo sistema público, utilizam apenas uma torneira para conseguir a água que será utilizada tanto para beber e cozinhar, quanto para a limpeza da casa, a lavagem da roupa e a descarga dos vasos sanitários. A opção de transferir a prestação de serviços para o setor privado vai acarretar a necessidade de também transferir recursos do Estado para a cobertura da não capacidade de pagamento dos custos de operação e margem de lucros, que o prestador de serviços privados requer. Mas isso ainda não é suficiente para a cobertura dos contingentes populacionais que estão fora dos sistemas públicos, ou a eles ligados de forma clandestina.

Portanto, em sociedades de extremas desigualdades, a opção de prestar o serviço de água por meio de entes privados não coloca em primeiro plano o enfrentamento do problema do acesso universal à água potável. Isso porque, em primeiro lugar, reconhece o usuário apenas como consumidor, e não como cidadão que tem direito ao atendimento de suas necessidades básicas. Em segundo lugar, não reconhece que as condições de inacessibilidade, ou acesso precário, não são apenas operacionais, de dificuldades eventuais de pagamento, mas, sim, de graves deficiências estruturais, tanto dos sistemas de engenharia quanto do padrão urbano e das moradias. 


\section{CONCLUSÃO}

Cenários de extrema pobreza e desigualdade ainda persistem em nosso país, mesmo em regiões providas de mais recursos econômicos e humanos como e o caso da Região Metropolitana de São Paulo. Principalmente em áreas rurais e urbanas carentes, denota- se a falta de acesso sustentável a agua potável, assim como carência de infraestrutura de saneamento, o que coloca a população local em situações de risco a saúde, tanto individual como coletiva, resultando no aumento da incidência de doenças infecciosas agudas e na prevalência de doenças crônicas, que acometem especialmente crianças, idosos, desnutridos e imuno deprimidos.

Nessas localidades, o acesso a serviços de saúde também e limitado, o que agrava ainda mais o quadro sanitário e compromete a qualidade de vida da população local. Esse panorama de iniquidade social, degradação ambiental e exclusão de serviços públicos básicos, verificado em áreas de exclusão social que abrigam populações humanas em situação de risco, precisam ser modificados. Para isso e necessário que se alcance melhores condições de governabilidade no sentido do desempenho do Estado e de governança na direção da interação com a sociedade, que enfoquem a implementação de politicas publicas de gestão integrada, envolvendo ações conjuntas e ajustadas nos setores de desenvolvimento urbano, habitação, saneamento e saúde e visando a promoção e proteção da saúde da população local e o enfrentamento da complexidade de fatores que evidenciam sua vulnerabilidade.

Para legitimar o seu papel protetor, o Estado também deve estender suas ações para atender às necessidades acima apontadas. Em outras palavras, o Estado deve reconhecer as situações de desigualdades de acesso e desenvolver políticas públicas para a sua resolução. O enfrentamento dos problemas de acesso à água potável envolve dois níveis de resolução. Num primeiro nível, há que ser considerado o caráter universal, de modo que seja garantido a qualquer pessoa o acesso a sistemas públicos de abastecimento de água potável. Num segundo nível, é necessário resolver, também, problemas de infraestrutura do ambiente domiciliar, de forma a compensar as desvantagens que famílias menos favorecidas sofrem por não disporem de condições para o armazenamento e manejo adequados da água em seus domicílios.

\section{REFERÊNCIAS}

ANA: Agência nacional das águas. Disponível em: < http://www.ana.gov.br/> Acesso em 08 de jun. de 2014.

ALOCHIO, Luiz Henrique Antunes. Direito do saneamento: introdução à lei de diretrizes nacionais de saneamento básico (Lei Federal n. 11.445/2007. Campinas: Millennium Editora, 2007, p. 66. Ibid, p. 12.

BRASIL. Ministério das Cidades. Saneamento ambiental 5. Brasília, DF, 2004.

DRENAGEM urbana. Pesquisa nacional de saneamento básico. Rio de Janeiro: IBGE, 2008. Disponível em: http://www.ibge.gov.br Acesso em: 03 jun. 2014.

HESPANHOL, Ivanildo. Água e saneamento básico: uma visão realista. In: REBOUÇAS, Aldo da Cunha; BRAGA, Benedito e TUNDISI, José Galizia (Orgs.). Águas doces no Brasil: capital ecológico, uso e conservação. 2. ed. São Paulo: Escrituras Editora, 2002, p. 251.

Indicadores de morbidade e fatores de risco. Disponível em: < http://www.datasus.gov.br > Acesso em: 08 jun. 2014

MENDONÇA, Mário Jorge Cardoso de; MOTTA, Ronaldo Seroa da. Texto para discussão nº 1081 . Saúde e saneamento no Brasil. Rio de Janeiro: IPEA, 2005, p. 01.

Ministério do meio ambiente. Disponível em: < http://www.mma.gov.br/> Acesso em: 07 jun. 2014.

Morbidades hospitalares 2007 em Mato Grosso do Sul. Disponível em: <http://www.ibge.gov.br>. Acesso 
em: 04 jun. 2014.

NOTÍCIAS. Crise da água perpetua e alarga desigualdades: falta de água e saneamento não só é reflexo do foço entre ricos e pobres como alarga essa diferença, diz representante do PNUD Brasil. Disponível em: < http://www.pnud.org.br> Acesso em: 10 jul. 2008.

Não há saúde sem saneamento. Disponível em: <http://www.esgotoevida.org.br> Acesso em: 06 jun. 2014.

RELATÓRIO de desenvolvimento humano 2007/2008. Combater as alterações climáticas: Solidariedade humana num mundo dividido, p. 257. Disponível em: < http://www.pnud.org.br> Acesso em: 03 jun. 2014.

Saneamento básico: essencial para saúde, economia e produção. Disponível em: <http://www. espacoecologiconoar.com.br> Acesso em: 06 jun. 2014.

TUCCI, Carlos E. M. Gestão da água no Brasil. Brasília : UNESCO, 2001, p. 129.

UNESCO: Organização das nações unidas. Disponível em: < $\underline{\text { http://www.unesco.org/new/pt/brasilia/> }}$ Acesso em: 04 de jun. de 2014. 